\title{
Interpupillary distance measurements for the African population of Polokwane in Limpopo province, South Africa
}

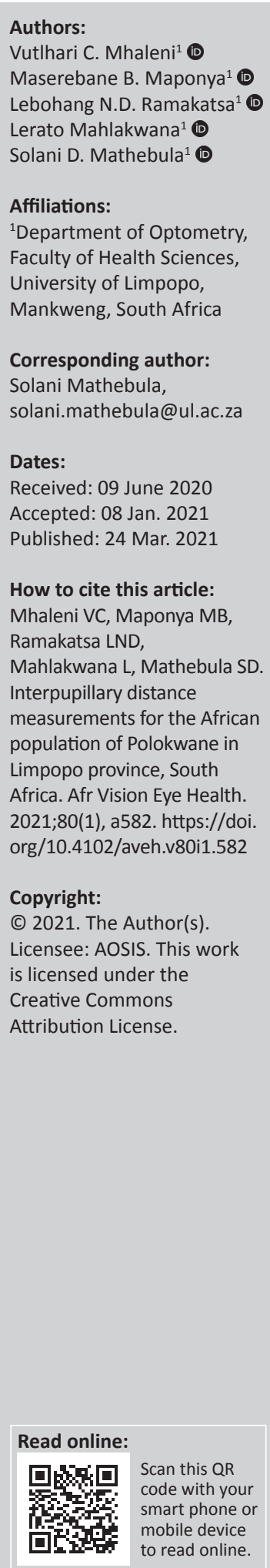

Background: Interpupillary distance (IPD) measurements are crucial as IPD needs to be considered before frame selection. The correct positioning of lenses before the eyes is very important to eliminate potentially undesirable prismatic effects from the lenses.

Aim: To investigate and report baseline or preliminary values and variations of IPD measurements amongst black South Africans.

Setting: The study was conducted in a privately owned optometric practice in Polokwane, Limpopo Province of South Africa.

Methods: This was a retrospective study conducted from 386 randomly selected record cards of patients seen in a private optometric practice. The record cards were selected randomly from patients who were examined by a single optometrist from 2017 to 2019 . The Statistical Package for Social Sciences (SPSS) was used for analysis.

Results: The study sample comprised of 386 participants, of which 214 and 172 were females and males, respectively. The mean IPD measurements were 67.2 millimetres $(\mathrm{mm}) \pm 3 \mathrm{~mm}$ and $64.2 \mathrm{~mm} \pm 3 \mathrm{~mm}$ for distance and near measurements, respectively.

Conclusion: The study provides preliminary or baseline IPD for black South Africans that can be used by the optical industry. The vast majority of adult IPD lie within the range $63 \mathrm{~mm}$ to $76 \mathrm{~mm}$. This study also established that there is a significant difference between distance and near IPD. On average, the near IPD is approximately $3 \mathrm{~mm}$ less than distant IPD. Knowledge of mean IPD is important in the design of optical devices and for the production of spectacle frames and lenses.

Keywords: interpupillary distance; African interpupillary distance; pupillometry; ocular anthropometry; inter-ocular anatomy.

\section{Introduction}

Interpupillary distance (IPD) or simply, pupillary distance (PD) is defined as the distance between the centres of the pupils of the two eyes of an individual, $1,2,3,4,5,6,7$ and is commonly expressed or specified in millimetres $(\mathrm{mm})$ but can also be stated in centimetres $(\mathrm{cm})$. Interpupillary distance is also associated with stereoscopic function and is one of the important orbital parameters for measuring the distance between the eyeballs. The mean IPD and/or its variation is needed in the design of most optical devices and the production of optical instruments that use binocular or stereoscopic input, such as slit lamps, binocular indirect ophthalmoscopes and spectacle frames and lenses. Both distance and near IPD measurements are necessary for proper design and placement of ophthalmic lenses, particularly multifocal lenses. There are two types of IPD, namely, the anatomical and physiologic IPD. ${ }^{2}$ Anatomical IPD refers to the distance between the two centres of the pupils, whilst the distance between the visual axes is called physiologic IPD. The anatomic and physiologic measurements may differ slightly in some cases because of factors such as measurement error.

There are two commonly used methods for measuring IPD in individuals. The most common method is a manual measurement with a simple millimetre rule, but a lesser used method involves the use of instruments called pupillometers that are sometimes digital. The pupillometer has an advantage over the simple rule because it can measure monocular IPD more accurately. ${ }^{8}$ The pupillometer is also necessary when spectacles of high powers or progressive addition lenses (PALs) are required because very precise centration of each lens along the individual's visual axes becomes essential. 
To eliminate unwanted strain on the eyes because of induced prismatic effects from the lenses, the correct positioning of ophthalmic lenses before the eyes is very crucial because the specific points on the lenses have to coincide with the correct location for the visual axes of both eyes and pupils. To the best of our knowledge, there is limited literature related to IPD measurements amongst the black South African population and Africans in general. The purpose of this study was to provide preliminary or baseline values and investigate variations of IPD measurements for Africans in general that can be used by eye care personnel in the ophthalmic industry, medicine and ocular anthropometry (the science and study of measurements and proportions of the human body).

\section{Methods}

This was a retrospective study carried out in a private optometric practice in Polokwane. The practice sees on average eight patients per day. Measurements for IPD were obtained from the clinical record cards of 386 randomly selected patients. The concerned optometrist has been conducting eye and vision examinations in this practice since 2012 and has been using a millimetre rule to measure the IPD for both distant and near vision.

Data collection occurred over one week in February 2020 and involved reviewing patient record cards of patients aged $20-80$ years. Data related to gender, age and IPD were reviewed and extracted from randomly selected patient record cards. Only record cards of healthy individuals who presented for refraction without any pathology were included. Record cards of individuals with facial abnormality, heterotropia, corneal and/or pupil disorders, orbital trauma or ocular surgery were excluded from the study. Only record cards for black South Africans of both sexes were eligible for inclusion in the study.

\section{Statistical analysis}

Statistical analysis was carried out using the Statistical Package for Social Sciences (SPSS) version 24 (IBM Corp., USA). The Kolmogorov-Smirnov (K-S) test was used to check for the normality of the measurements in addition to measures of skewness and kurtosis. The Shapiro-Wilk test is more appropriate method for sample sizes less than 50 . Descriptive statistics (mean and standard deviations) and mean differences were used to describe the results for this study. A $p$-value of less than 0.05 was considered statistically significant.

\section{Ethical considerations}

As this was a retrospective study of the identified data, informed consent was not required but the study was nonetheless approved by the Turfloop Research Ethics Research Committee (TREC) of the University of Limpopo (Ethical clearance number: TREC/196/2015:IR) and permission to collect measurements was granted by the manager (EJ) of the practice concerned.

\section{Results}

The K-S tests indicated that the IPD measurements were essentially normally distributed. The sample included 386 participants aged $20-80$ years and there were 214 females and 172 males. The mean age and standard deviation (s.d.) for the whole sample were $48.86 \pm 15.2$ years $(49.0 \pm 15.9$ years for females and $48.69 \pm 14.3$ years for male participants). Table 1 shows the descriptive statistics for the distance and near IPD measurements for the various variables of interest. The mean distance IPD was $67.2 \mathrm{~mm} \pm 3 \mathrm{~mm}$ whilst the mean near IPD was $64.2 \mathrm{~mm} \pm 3 \mathrm{~mm}$. The mean difference was $3.00 \pm 0.6$ (confidence interval [CI]: 2.9-3.1) $\mathrm{mm}, r=0.98$ with $p=0.00$.

The boxplot (box and whiskers plot) is a graphical method for presenting group(s) of measurements with the use of quartiles and either means or medians. Figure 1 shows the distribution of IPD measurements for distance and near vision. The boxplot is also very useful in visualising skewness in measurements. A normal or symmetric distribution has equal proportions of measurements around the mean or median (the bold horizontal line in the middle of the box). Positive skewness is seen when the median (and/or mean) is closer to the lower or bottom quartile. A distribution that is negatively skewed is shown by the box with a median (and/or mean) closer to the upper or top quartile. The skewness (and kurtosis) of any normal univariate distribution is zero. Thus, Table 1 indicates mild positive skewness and leptokurtosis for IPD despite the results for the $\mathrm{K}-\mathrm{S}$ tests that suggested data normality. Samples with low kurtosis tend to have fewer outliers whilst with higher kurtosis there are usually more outliers (or extrema).

The histogram is an effective graphical technique for showing both the skewness and kurtosis of measurements. The distribution of the distance IPD measurements for all participants is shown in Figures 1 and 2. Most distance IPD measurements $(70 \%)$ were between $64 \mathrm{~mm}$ and $68 \mathrm{~mm}$. Most near IPD measurements were approximately $63 \mathrm{~mm}$ (see Figures 1 and 3). Figures 4 and 5 show the distribution of distance and near IPD measurements by gender. A statistically significant difference was observed amongst female and male participants. As anticipated, male participants, on average, had wider or larger IPD measurements than females.

TABLE 1: Descriptive statistics of interpupillary distance measurements for 386 African participants from Polokwane, Limpopo, South Africa.

\begin{tabular}{lcccc}
\hline Parameters & Mean \pm s.d. & Ranges & Skewness & Kurtosis \\
\hline Age in years & $48.86 \pm 15.2$ & $20-80$ & 0.0 & -0.9 \\
Distance IPD & $67.2 \pm 3.0$ & $58-78$ & 0.7 & 1.7 \\
Females & $66.5 \pm 2.4$ & - & - & - \\
Males & $68.0 \pm 3.4$ & - & - & - \\
Near IPD & $64.2 \pm 3.0$ & $51-74$ & 0.4 & 1.1 \\
Females & $63.5 \pm 2.3$ & - & - & - \\
Males & $66.0 \pm 3.5$ & - & - & - \\
\hline
\end{tabular}

IPD, interpupillary distance measurements; s.d., standard deviation. Note: Units are in millimetres $(\mathrm{mm})$ except for skewness and kurtosis that are unitless. Normally distributed data would have skewness and kurtosis of zero or near zero. Bold indicates that there was a significant difference between distance and near interpupillary measurements, and between females and males, $p<0.05$. 


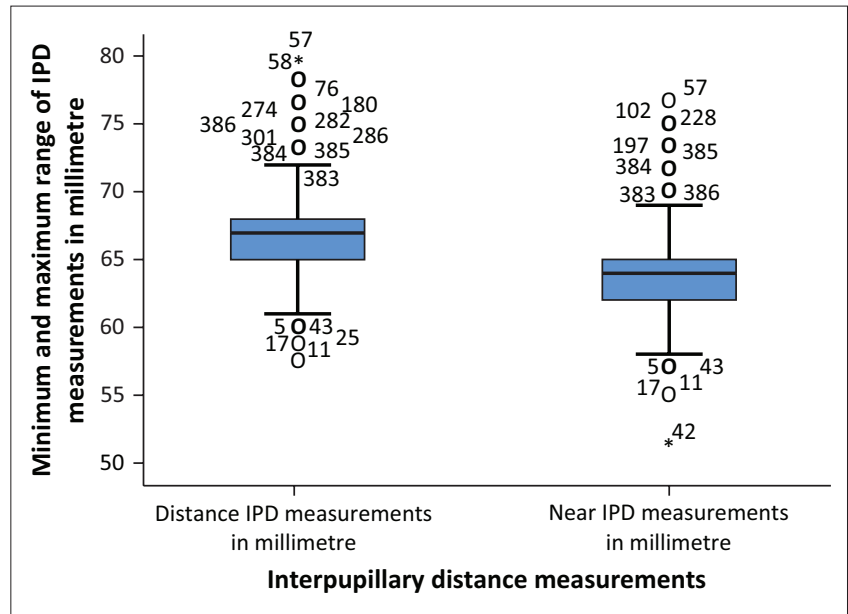

IQR, interquartile range; IPD, interpupillary distance measurements.

The circles are outliers (either more or less than $1.5 \times$ IQR) whilst asterisks are extrema (either more or less than $3 \times$ IQR). Participant's numbers are also included for possible outliers and extrema.

FIGURE 1: Two boxplots for distance and near interpupillary distance measurements in millimetres with whiskers from minima to maxima.

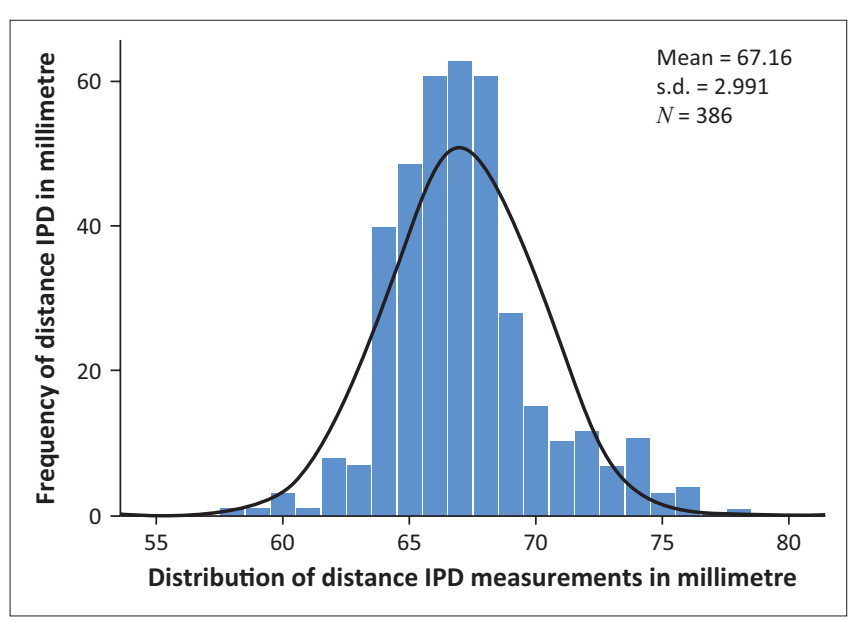

IPD, interpupillary distance measurements; s.d., standard deviation.

FIGURE 2: Frequency histogram showing the distribution of distance interpupillary distance measurements in millimetres for 386 African participants.

\section{Discussion}

The periocular measurements of the human body can be affected by many factors, including geographical region, race or ethnicity, gender and age. Knowledge of baseline and normative IPD is important in determining the degree of deviation from normal. The entrance pupil determines the amount of light that enters the eye and stimulates the retina. Interpupillary distance is important, when placing spectacle lenses in front of eyes, to prevent undesirable or unwanted prismatic effects. $910,11,12,13,14$ It has been reported that measurements of IPD is one of the craniofacial features that alters in certain craniofacial syndromes and IPD is useful in the management of post-traumatic orbito-facial deformities. ${ }^{9,15,16}$ The normal values of IPD and craniofacial features are also used in the evaluation of ocular hypotelorism and hypertelorism. ${ }^{15,16}$ Interpupillary distance could also be used reliably in selecting maxillary anterior teeth for prosthodontics. ${ }^{15}$

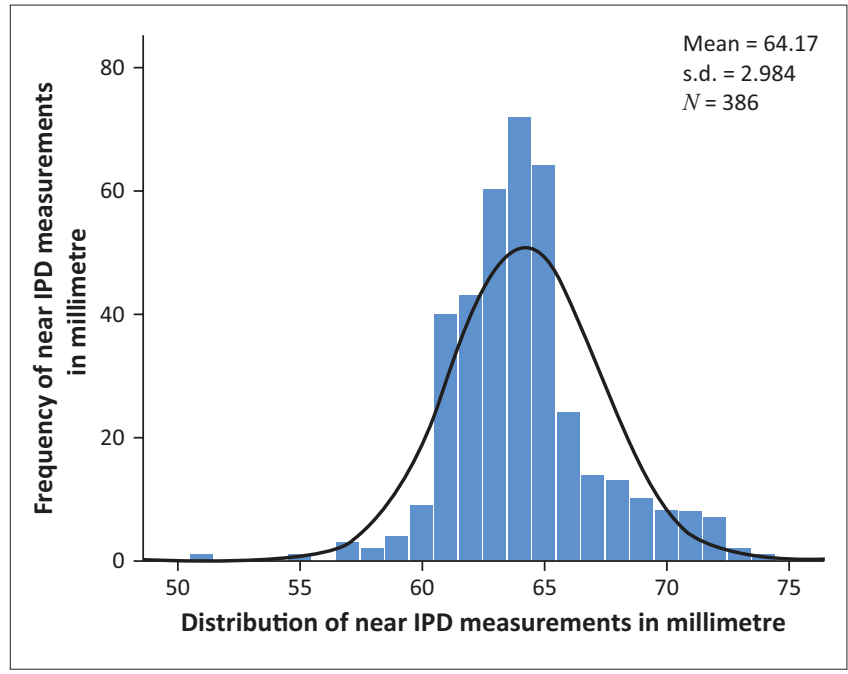

IPD, interpupillary distance measurements; s.d., standard deviation.

FIGURE 3: Frequency histogram showing the distribution of near interpupillary distance measurements in millimetre for 386 African participants.

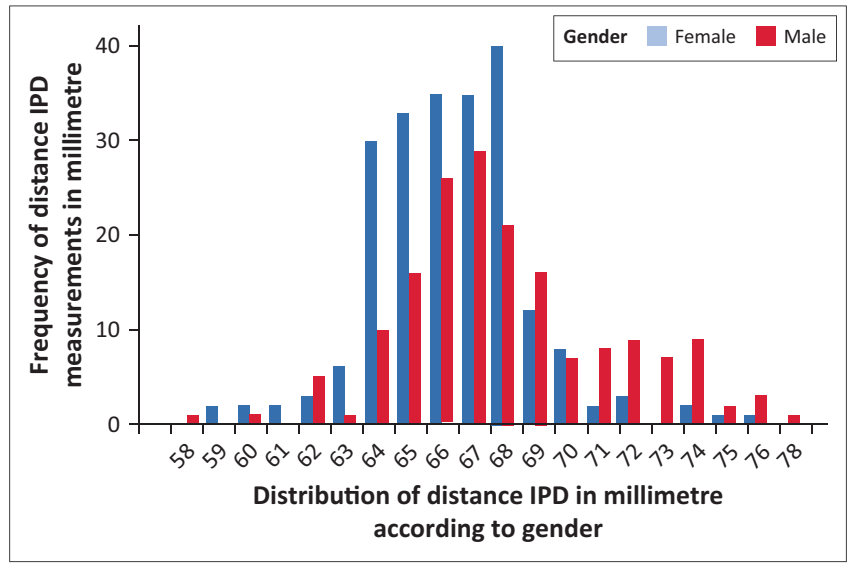

IPD, interpupillary distance measurements.

FIGURE 4: Bar chart showing the distance interpupillary distance measurements in millimetre for 214 females and 172 males of African participants.

The distance IPD is measured when the eyes are focused at optical infinity. The average international standard for distance IPD is $63.5 \mathrm{~mm}$ and can vary from $58 \mathrm{~mm}$ to $70 \mathrm{~mm}{ }^{6}$ The results of this study showed that the mean distance IPD for black South African sample under investigation was $67.2 \mathrm{~mm} \pm 3.0 \mathrm{~mm}$ with a range of $58 \mathrm{~mm}-78 \mathrm{~mm}$ (see Table 1 and Figure 2). Kumah et al. ${ }^{1}$ found a mean distance IPD of $65.5 \mathrm{~mm} \pm 3.5 \mathrm{~mm}$ amongst university students in Ghana. Interpupillary distance has been reported to differ amongst races and a study conducted amongst Caucasians, Asians, African-Americans and Mexican-Americans by Pivnick et al. ${ }^{16}$ found that the mean distance IPD was significantly greater for blacks rather than whites of similar age. Alkhairy et al. ${ }^{17}$ reported a mean distance IPD of $61.4 \mathrm{~mm} \pm 4.3 \mathrm{~mm}$ amongst the Pakistani population. Rasengane and Carlson ${ }^{18}$ in a conference abstract reported a distance mean IPD of $67 \mathrm{~mm} \pm$ $0.5 \mathrm{~mm}$ (range: 58-74) amongst South African rural Africans.

The distance IPD is useful for the horizontal placement of optical centres of spectacle lenses before the entrance pupils of the eyes in primary gaze. This is important to position the 


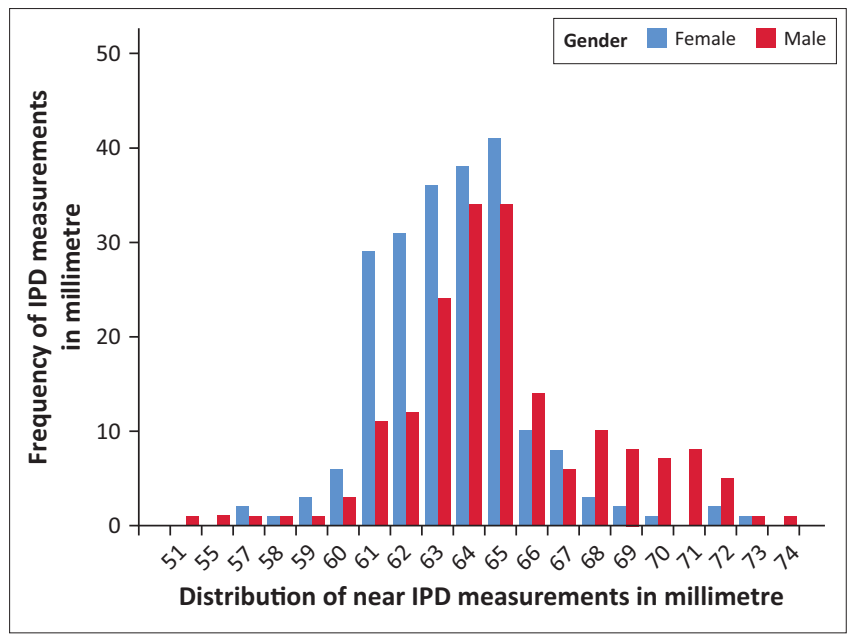

IPD, interpupillary distance measurements.

FIGURE 5: Bar chart showing the near interpupillary distance measurements in millimetre for 214 females and 172 males of African participants.

optical centres of the lenses before the eyes when performing subjective refraction. The amount of binocular convergence needed for bifoveal fixation of a target is related to the distance IPD through ${ }^{18,19}$ :

Convergence $(\Delta)=\frac{\text { Distance IPD }(\mathrm{cm})}{\mathrm{d}(\mathrm{cm})}$

where $d$ is distance in centimetres of the target plane from the midpoint between the centres of rotation of the eyes, which is normally $13 \mathrm{~mm}$. An incorrect or not specified IPD during placement of lenses in frames can result in decreased image quality because of aberrations and distortion ${ }^{19,20}$ and convergence may be affected.

The near IPD is important to determine the nasal decentration of multifocal segments and the near zone of PALs into their inferior position before the eyes. This study showed that the mean near IPD was $64.2 \mathrm{~mm} \pm 3 \mathrm{~mm}$ with a range of $51 \mathrm{~mm}$ - $74 \mathrm{~mm}$ (see Table 1 and Figure 3). The mean difference between the distance and near IPD was approximately $3 \mathrm{~mm}$. If the IPD is off by the slightest bit with high-powered lenses, this can lead to unwanted prismatic effects. If a patient requires a pair of single vision reading lenses, then the near IPD should be used so the patient can view through the optical centre of the lenses when doing near work to prevent induced prismatic effect that the patient will get if a wider distance IPD is used instead of the actual near IPD.

In this study, the mean IPD measurements for males was larger than for females, $p<0.05$ (see Figures 4 and 5). Several studies have reported that mean IPD of the male individuals are greater than those of females..$^{9,10,11,12,13}$ The results of this study are in agreement with other studies that male IPD is wider than those of females. ${ }^{9,10,11,12,13,14}$

The reason is unknown but could be attributed to the fact that adult males may have larger craniofacial skeletons than females. Studies by Quant and $\mathrm{Woo}^{21}$ also found that distance IPD amongst males ranged from $55 \mathrm{~mm}$ to $70 \mathrm{~mm}$ and $56 \mathrm{~mm}$ to $66 \mathrm{~mm}$ for females. In South Africa amongst whites, Butler et al. $^{22}$ found mean near IPD to be $59.04 \mathrm{~mm} \pm 2.9 \mathrm{~mm}$ for females and $61.59 \mathrm{~mm} \pm 3.1 \mathrm{~mm}$ for males from a private optometric practice. A study in Nigeria by Oladipo et al..$^{23}$ amongst adult Ijaws revealed a mean IPD of $69.8 \mathrm{~mm}$ and $66.4 \mathrm{~mm}$ for males and females, respectively.

Possible limitations of this study in Limpopo (SA) included the relatively small sample size, which is not necessarily a true representation of black South Africans. The study was conducted in a single optometric practice and thus the sample is clinically based. So, further studies are recommended that will encompass larger sample sizes and perhaps many optometric practices and hospitals, and/or randomisation from the general African population across a wider geographic region of South Africa or perhaps of Africa itself.

\section{Conclusion}

The study provided preliminary or baseline (reference) IPD measurements for an African sample (from the black South African population) that can be used by the optical and ophthalmic industries and others. It is important for clinicians to accurately measure the IPD before assessing the visual system and prescribing suitable optical devices without undesirable effects.

It is particularly important for clinicians to accurately measure the near working distance IPDs for individuals with distance IPD greater than $70 \mathrm{~mm}$. This is because such an individual has to converge more for, say, a $40-\mathrm{cm}$ working distance than individuals with smaller distance IPD measurements. This is vital for prescribing PALs. Conventional PAL work on an average for distance IPD of about $64 \mathrm{~mm}$, which means that the near IPDs corridor inset is about $2 \mathrm{~mm}$ in each eye given a $60 \mathrm{~mm}$ near IPD. ${ }^{24,25}$ People with larger distance IPD measurements have difficulties adjusting to these lenses if they want to work at $40 \mathrm{~cm}$. Understanding IPD more fully in different populations will assist towards better designs for PAL and greater satisfaction and comfort for patients that require such lenses for their visual needs.

\section{Acknowledgements}

The authors thank the owner and manager of the optometric practice concerned for allowing them to assess and use the relevant data from their patient record files. Funding from South African Medical Research is also kindly acknowledged.

The article is based on data from one of the fourth-year optometry student research projects at the University of Limpopo.

\section{Competing interests}

The authors declare that they have no financial or personal relationships that may have inappropriately influenced them in writing this research article. 


\section{Authors' contributions}

V.C.M., M.B.M., L.N.D.,R., L.M. and S.D.M. contributed equally in conceiving, designing, collecting and analysing data and writing the manuscript.

\section{Funding information}

The study was funded by the South African Medical Research Council to S.D.M., under capacity building.

\section{Data availability}

Data sharing is not applicable to this article.

\section{Disclaimer}

The views and opinion expressed in this article are those of the authors and do not necessarily reflect the official policy or position of any affiliated agency of the authors.

\section{References}

1. Kumah DB, Akuffo KO, Abaka-Cann JE. Interpupillary distance among students in the Kumasi Metropolis. Optom Open Access. 2016;1(1):a103. https://doi.org/ 10.4172/2476-2075.1000103

2. Osuobeni EP, al-Fahdi M. Differences between anatomical and physiological interpupillary distance. J Am Optom Assoc. 1994;65(4):265-271.

3. Murphy WK, Laskin DM. Intercanthal and interpupillary distances in the black population. Oral Surg Oral Med Oral Pathol. 1990;69(6):676-680. https://doi. org/10.1016/0030-4220(90)90346-T

4. Holland BJ, Siderov J. Repeatability of measurements of interpupillary distance. Ophthalmic Physiol Opt. 1999;19(1):74-78. https://doi.org/10.1046/j.1475-1313. 1999.00400.x

5. Osuobeni EP, Faden FK. Interpupillary distance of females of Arab origin. Optom Vis Sci. 1993;70(3):244-247. https://doi.org/10.1097/00006324-19930300000012

6. Dodgson NA. Variation and extrema of human interpupillary distance. Proc SPIE. 2004;5291:36-46. https://doi.org/10.1117/12.529999

7. Esomonu UG, Taura MG, Anas IY. Anthropometric studies of the interpupillary distance among the Igbos of South Eastern Nigeria. Bayero J Pure Appl Sci. 2012;5(1):123-126. https://doi.org/10.4314/bajopas.v5i1.22
8. Pryor HB. Objective measurements of interpupillary distance. Paediatrics. 1996; 44(6):973-977.

9. Yildirim Y, Sahbaz I, Kar T. Evaluation of interpupillary distance in the Turkish population. Clin Ophthalmol. 2015;9:1413-1416. https://doi.org/10.2147/OPTH. S85584

10. Fesharaki H, Rezdei L, Farrahi F. Normal interpupillary distance values in an Iranian population. J Ophthalmic Vis Res. 2012;7(3):231-234.

11. Osuobeni EP, al-Musa KA. Gender differences in interpupillary distance among Arabs. Optom Vis Sci. 1993;70(12):1027-1030. https://doi.org/10.1097/00006324199312000-00006

12. Pointer JS. The interpupillary distance in adult Caucasian subjects, with reference to 'readymade' reading spectacle centration. Ophthalmic Physiol Opt. 2012; 32(4):324-331. https://doi.org/10.1111/j.1475-1313.2012.00910.x

13. MacLachlan C, Howland HC. Normal values and standard deviations for pupil diameter and interpupillary distance in subjects aged 1 month to 19 years. Ophthalmic Physiol Opt. 2002:22(3):175-182. https://doi.org/10.1046/j.14751313.2002.00023.x

14. Barreto RL, Mathong RH. Orbital measurement in black and white populations. Laryngoscope. 1999;109(7):1051-1054. https://doi.org/10.1097/00005537-1999 07000-00007

15. Singh JR, Banerjee S. Normal values for interpupillary, inner canthal and outer canthal distances in an Indian population. Hum Hered. 1983;33(5):326-328. https://doi.org/10.1159/000153399

16. Pivnick EK, Rivas ML, Tolley EA. Interpupillary distance in a normal black population. Clin Genet. 1999;55(3):182-191. https://doi.org/10.1034/j.1399-0004. 1999.550306.x

17. Alkhairy S, Siddigui $F$, Hassan $M$. Orbitofacial anthropometry in a Pakistani population. Pak J Ophthalmol. 2016;32(1):41-47.

18. Rasengane TA, Carlson AS. Corneal curvature and interpupillary distance measurements in a South African rural black population. Optom Vis Sci. 2001;78(12):85. https://doi.org/10.1097/00006324-200112001-00118

19. Griffin JR, Borsting EJ. Binocular anomalies: Theory, testing, and therapy. 5th ed. Santa Ana, CA: OEP Foundation; 2010.

20. Goss DA. Accommodation, convergence, and fixation disparity: A manual of clinical analysis. 2nd ed. London: Butterworth-Heinemann; 1995.

21. Quant JR, Woo GC. Normal values of eye position in the Chinese population of Hong Kong. Optom Vis Sci. 1992;69:152-158. https://doi.org/10.1097/00006324199202000-00009

22. Butler MA, Jowell ME, Clarke-Farr PC. Analysis of readymade readers and nearinter-pupillary distance for presbyopic patients in optometric practice in Cape Town, South Africa. Afr Vis Eye Health. 2016;75(1):a316. https://doi.org/10.4102/ aveh.v75i1.316

23. Oladipo G, Okoh P, Hart J. Anthropometric study of ocular dimensions in adult ljaws of Nigeria. Res J Med Sci. 2010;5(2):121-124.

24. Bhootra AK. Dispensing optics. London: JP Medical Ltd.; 2015.

25. Brooks C, Borish I. Systems for ophthalmic dispensing. 3rd ed. London: Butterworth-Heinemann; 2006. 